\title{
Regulation of the Dessolution Marriage Consequences by the Prenuptial Agreement
}

\section{Blerina DODAJ}

PHD Cand., EUROPEAN UNIVERSITY OF TIRANA, lawyer

\begin{abstract}
The statistics shows an increase of divorce number, assigns each of us, scholars of the law, lawmakers, applicators of the legal norms, to find an appropriate way to regulate every consequence that derives from the process of divorce. It is obvious that the known social problem of divorce affects a considerable number of subjects, starting from those directly implicated in the process or other third persons, whom interacted in a way or another with the subjects of the divorce itself. This process directly affects the spouses and children, if there are any, by considering for them not only the conclusion of an actual status but also as the beginning of a new life that both have its bright and dark aspects.
\end{abstract}

Keywords: Regulation of the Dessolution Marriage Consequences by the Prenuptial Agreement.

\section{Introduction}

In our legislation, more accurately in the family code chapter III ${ }^{1}$, that we can note are the consequences of dissolution of marriage, according the parties involved in this process. Starting from the usage of the maiden surname for women, contribute compensation, usage familiar apartment, child alimony support, obligation of growth and education of children. The institution in charge in the Civil Court, which takes the maximal care and effort in providing justice for the dissolution of conflicts of this nature, by analyzing very carefully every element in order to properly regulate the consequences of the dissolution of marriage for both spouses, and most importantly for the minors, for the whom the court the court has their best interest a priority. The confrontation with the process of marriage dissolution engages both spouses to properly reconsider and deeply analyze all the consequences that will derive from the process of divorce since they may be under pressure and not always be able to reason at their best. The Marriage contract gives them the opportunity to regulate these outcomes and solute the conflicts at their best interest, at the beginning of the marriage or during the optimal continuance of the marriage.

The object of the prenuptial agreement, can't be marginalized only in the regulation of physical and monetary goods, because the freedom of spouses to behave as they want can not affect the obligations and rights that derive from the concept of marriage itself, as child responsibility, regulation of legal administration and custody. However other such as, the house, food obligation, supplementary compensation, are all elements that can be all, in absence of conflict, perfectly regulated in the prenuptial agreement. The Prediction of the effects of the divorce should be treated as a way of protection for the subjects affected by the process, because each of the spouses can decide for better terms, in the case both spouses consent, at the moment of conflict.

\section{LEGAL FORECAST OF MARRIAGE DISSOLUTION CONSEQUENCES}

All cases of divorce, subject to the consequences of social, psychological, economic and most importantly legal ones. Concretely, within the effects it is clear that only the legal ones are inevitable and are rational assissment elements who court decides only through its main function for our justice. The low in the Family Code, Chapter III, are expressly provided the dissolution of marriage, ranking them by nature and by entities. Analyzing the subjects involved in the process of marriage, specifically spouses and subsequently followed by children, if there are, is predicted the way they will be governed primarily economic relations, housing and takeing care of children and keep these reports in the best interests of the

\footnotetext{
1 Law 9062, date 08.05.2003 "Family Code", Article 145-162
} 
children. Referring to the provisions of the consequences of divorce for spouses and consequences of divorce for children. These divisions of this nature, the legislator made them by analyzing who directly affects and where it is necessary to become legal intervention to avoid inequities, abuses and further damage that may be caused to family members of dissolution of marriage.

All the protection that law provides in case of this nature, it is protection provided to the family and sensibilitiy that this institute of law regards to its social aspect. This protection is attributed to the family life as one of the four dimensions of an individual personal life ${ }^{1}$, highlighting the importance of the family and any action to damage her. One of the ways of making family life is marriage, which is the basic of family unity ${ }^{2}$, and the latest interepretion of European case law, this is not limited to gender or number expanding so the potential of creating family and consequently extending the legislation which will regulate these new relations to family members. By thinking about the importance of family life and ruin it, and returning the family members to the previous legal status in society, there are enough consequences, as much as apparently it is like a challenge the fulfillment of judicial entities which are affected by solution marriage to integrate into society without social distinction. Verily, this is why law interferes by predicting what are the inevitable consequences that the members of the family can have after divorce, providing them legal guarantees for the surname, residence, economy as well as mutual economic assistance or even the possibility of maintaining family relations after divorce. Iterpretations that our law makes, to the consequences related to spouses and consequences related to children we can notice institutes of law, who come to help the "weakest" parent, and help the children in their best interest. Since the literal interpretation of legal regulation "consequences of divorce" begins the first consequences, concretely the dissolution of marriage, at the moment there is no more marriage and the willpower of the spouses is concentrated in the change of their status. Changes which accompanied the impact on the data of their identity, concretely the dissolution of the marriage, the spouse who had changed his name to respect marriage, already regains his surname before marige. Immediate impact and directly identifying husband's surname as amended, which in practice translates into administrative complication of procedures relating to the representation of himself with other persons. Not only genuine change of identity, but also the complication of access and benefits, legal attributed to any citizen, but in this case is more complicated for the person who changed the surname. This process in the face of third parts, putted in doubt unity of the two surnames in a person, a phase which will last for as long as we will the recovery last.

The second consequence, respect to spouses, can be considered a repairmand to spouse whome can be harmed or caused a difference in dissolution of marriage. Specifically, it is the compensation contribute, the institute which has a considerable force, that in a few cases can be found the terminology "the court can force ..." 3 the head because of interference in family relations juridicial structure is always prudent and there is place for recomandation in the solution that can deliver the court in the interpretation of this provision it is clear that legislative intervention is in order to protect the spouse that could be more damaged by the divorce. It is worth explaining what we mean by husband injured after legal treatment consists in the economic concept, where inequality in provision states that creates the dissolution of marriage with regard to division of property. This divided provision is a bit confusing, since our legislation, the trial of marriage dissolution is in a second phase and it may not be possible to predict at the moment of dissolution of marriage, except as provided dissolution of marriage by mutual consent of the spouses, with the signing of the agreement determines the spouse $^{4}$ who created a kind of inequality. Pursuant to Family Code, Article 149 clarify what are the elements to be brought to the attention of the Court to determine the compensation, but again these are not related to the division of assets and judicial investigation of these elements can not be compleded.

Last consequences for the spouses, in the process of dissolution of marriage has to do with the apartment, which has accompanied almost always spouses in divorce, creating more damages. The weakest spouse, unsupported remains with no shelter, only as a result of dissolution of marriage. The contribution of the husband in the family may have been different, but whether the legislation would not intervene, can be considered incalculable and social consequences can be heavy bt not integrating him/her into the society. This right is not an priority, as required condition to benefit from this provision are substantial, estimated depending on the other elements, facing opportunities and not always fulfill these conditions, where

\footnotetext{
${ }^{1}$ Article 8, European Convention of Human Rights

2 Article 1, Family Code, number law 9062, date 08.05.2003

${ }^{3}$ Article 147, Family Code, number law 9062 date 08.05 .2003

${ }^{4}$ Neni 125 Kodi I Familjes, number law 9062 date 08.05.2003
} 
the provision become applicable.

Other consequences of the divorce dealing with the second group of subjects, the children, as I mentioned above, if there are children from a previous marriage,the attention to the problems that may cause to them is moved mainly to youngers. The legal treatment, inspired by the principle of respecting the highest interest of the child, tries to predict and regulate in law, the way of exercising parental responsibilities, visits with the other parent, alimony. Elements that the court in these cases can not evaluate alone after making investigation with the evidences presented in the court,sets psychologists or sociologists experts to give their opinion about the divorce effects on children.

\section{THE CONSEQUENCE REGULATIONS OF PRENUPTIAL AGREEMENT}

The prenuptial agreement object, can not be confined only to the regulation of property regime, as long as the freedom of the spouses to operate with their commitments in the marriage, can not avoid the rights and obligations that derives from the marriage, parental responsibility, rules of legal administration and custody, while the apartment, having food, the compensation, etc. are absolutely all elements which, are all better regulated in the absence of the conflct than the final judgment. The forecast of marriage dissolution consequences in the prenuptial agreement should be seen as a defense for the subjects affected in this process, because each spouse can decide better in terms of understanding with the other spouse, rather than in the confrontational moment.

During the development of the legal process of divorce, the problems encountered by the spouses are the protection of their rights as well as those of the children, because each spouse being in conflict makes them only the litigants forgetting their membership in a family. Precisely, the prediction of how to deriv the consequences of divorce after marriage, in these subjects are a family of their own and take this status as efficient both, for spouses as well as for the children. Each member of the family, getting protected, and feeling it more than being forced, makes dhe sposes go to divorce and not avoid it, if the marriage has lost its sense and its purpose. The nature of the prenuptial agreement, accommodates consequences of divorce, because besides how to fix wealth increased during the marriage and will develop autonomy property of each spouse, it is possible to predict and that during the course of life spousal predisposition of everyone who has to take the consequences that flow from marriage. Guarantee regulation of the consequences of the dissolution of marriage in the prenuptial agreement is not only the final moment but at the beginning of the marriage, each spouse may feel more protected in relation to his position during the marriage without impeding any moment his will about continuing his marriage might be damaged after the divorce. Cases from practice show that the "weak" spouse avoid seeking divorce because it is not safe about his house after the divorce is not sure whether his children will have the opportunity to get feed by the other spouse and almost never spouses not benefit from the compensation in the process of dissolution of marriage, in some cases on issues probative, in some other time and some reluctance by the lack of information.

So, forecast that in the prenuptial agreement obligations after the marriage dissolution, should be taken as a guarantee for the weaker spouse and the protection of the children involved in divorce. None of the parents can not give up in alimony to his children, but often the tribunal process of marriage dissolution has not been positive approached by the spouses, with the understanding of their marriage dissolutions, and consequently this is reflected in the only juridical remedies that they have to oppose each other, forgetting the obligations that they have from this kind of phase, and automatically is damaged the highest interest of the child, to obtain a higher food pension or to rate as right as possible the leaving for their raising and education, or the way of the visits with the other parent. There are a few cases where children who are raised and educated by their mother, have a radical change of their living, going away from their apartment, often they remain homeless because this has not found the good willpower of their father and therefore what the law provides the court can not guarantee. In the existence of the prenuptial agreement, this forecast would be for both spouses and for children, considering this space in the prenuptial agreement a form of legal reserve, without promoting and without impeding divorce, except that improving the status of each subject involved in the dissolution of marriage,except tribunal process.

As the consequences above are discussed, explaining the precedence that the law does to the phenomen, to reduce a little the damage for the subject more damaged to the one considered less damaged, practice has shown that the importance of regulation of these consequences is considerable, as the spouses at this phaze of dissolution of the marriage are not limited only to the loss of the willpower to cooperate to simplify the life of eachother, but this problem has been evolved damaging also the children in different ways from their illegal behaviour. Often, in the Republic of Albania, the parent who has the children to raise and educate, abuses with this right and duty that the court has given to them by using the children to attract attention or revenge against ex-spouse. In the absence of the willpower to implement the decision of 
the court, our legislation, is not enough only with the consequences regulation,but also has expected sanctions by the not implementation,particularly in criminal law there are specific provisions that sanction this kind of behaviors, "Denial of livelihood "1" Illegal taking of a child "2," Preventing the execution of court decision "3, previsions which belong to the actors of these injustices, affecting court decisions that have given justice in a conflict resolution. This rating, is joined to the purpose of this work about the importance of the legal consequences $t$ of marriage dissolution in the prenuptial agreement. By not focusing on concrete elements of the contract of marriage, about the object, subject, scope, implementation and the legal power that it has, as already known, in a section of its forecast of these consequences would by analogy, almost like the agreement envisaged in our legislation ${ }^{4}$, to the dissolution of marriage by mutual consent of the spouses since it is an act which is formulated precisely in the final moment of marriage. Prediction of this way of divorce, with the request of the both sides conditioned by legislation from the deposition of an agreement, which regulates the consequences of divorce. The prenuptial section, forecasted as the consequences of the dissolution of marriage and agreement for dissolution of marriage by mutual consent differs because the different moments in which are formulated. The first one, has to do with the regulation of each consequence during the marriage about the economy, the administration except those that the law forbids spouses to decide by themselves and the other to predict as will be operated for each spouse, at the time of connection marriage, in the other hand the second has to do with the regulation of the consequences of the dissolution of marriage just as the spouses by their own free will an mutual ,too, when they think that marriage should not proceed, they propose to the court a draft agreement, not only for the marriage resolution, but also for the regulation of the consequences of the divorce.

In this point consist not only the difference, but also the importance of consequences forecasting, in a calmer moment and productive terms of clarity of judgment and goodwill in the responsibilities incurred from this process. In the marriage contract, they can fix problems related to the surname, setting common surname or each of the spouse can maintain his surname, if the marriage is dissolved, in this way eliminating the uncertainty about how will be the surname of each spouse conditioned on progress of the couple, this element which can stop each of the partners to take on personal activities.

During the marriage, the Involvement in the different activities, can be spacious and the surname changing consequences, has conditioned the decision to end this formal marriage, behalf of realizing the social and intellectual aims. Often this legal element has been used as oppression to maintain the marriage against the free will of the other spouse, as a result of identity documents, activities abroad, or their opportunities for professional growth. Regulation of this consequence, when the spouses are calm with each other and in full harmony, in the moment of the wedlock, it doesn't leave any space to use the surname as a chantage for the dissolution of marriage.

Particular importance in consequences addressing, has the compensatory allowence, as the newst element of the last code, in support of the spouse, considered the most damaging spouse, to eliminate the most serious consequences in life after marriage.

The forecast of this element in the prenuptial agreement, should be considered as a higher level of understanding of the spouses, to the point that it may seem like deletion the consequence of any thought of dissolution of marriage.

Spouses in the prenuptial agreement, can not know exactly which of the spouses in case of divorce, will be weaker and will be considered affected by the divorce, but the forecast of this element in the contract, receives an other form, in the context of goodwill for the commitment and willingness that takes each of the spouse, to accept the payment of the compensation contribute in the interest of the other spouse, that in the moment of the marriage dissolution should be considered damaged.

Once again evaluation of the legal elements that has sanctioned the Family Code Article 149, relating to age, health status, time spent in regard with raising children, predisposition for new jobs, etc. is the right of the court to decide, and can't be a priori applicable. To set the concrete amount of the compensation contribution, is a right that belongs to the court, evaluating the elements in the moment of the marriage dissolution. Juridical value of forecast of this consequence since in the prenuptial agreement, has valuated as a double protect, which is offered to the damaged husband after the divorce, not only by law but also mutual free will of spouses in the contract approved the security of each spouse after the divorce.

\footnotetext{
${ }^{1}$ Article 125 of Penal Code, number law 7895, date 27.01.1995

2 Article 127 of Penal Code, number law 7895, date 27.01.1995

${ }^{3}$ Article 320 of Penal Code, number law 7895, date 27.01.1995

${ }^{4}$ Article 125 of Family Code, number law 7895.date 08.05.2003
} 
Which may be the attitude of the spouses in a prenuptial agreement, in relation to the right for the dwelling use? At the time of the prenuptial agreement execute, the spouses may have or not have wealth, in any case is worth addressing this element in the contract, by providing a fundamental right to the spouse. Firstly we should clarify what is called family accommodation? For this comes to our aid the European jurisprudence, the interpretation of the ECHR of Article 8 of the ECHR, considering the home an element of private life, and the complaints concerning the observance of this right, this court has expanded the interpretation of family home ${ }^{1}$, considering it an environment where the spouses have chosen to live, despite the extensive overseas operations, which can carry out entities that use this home, but their stay and includes its peaceful possession. In the prenuptial agreement the spouses can predict how it will be resolved this consequence, to not refuse to each other a fundamental right and not just to them but if they have children much more prevails the necessity of securing the home for the children, avoiding the differences that can be caused to the children after the parent divorce.

In case that the spouses by their own free will, determine in the prenuptial agreement, who will be considered family home and this home should exist in the moment of the contract signing, so the regulation of this consequences in the prenuptial agreement, becomes more possible and more specific and takes the appropriate values, as a guarantee that is required for each spouse and for the children, too. This sort of problematic consequences, has a special treatment because the children relation, that are often the victims of this process, even though the legislation has labored to provide them, the legal guarantees, defending the principle of the highest interest of the children, the practice has shown that the goodwill of parents is crucial in this stage of their rehabilitation. Based in the free will principle in contract signature, the prenuptial agreement, represents the highest form of expression of the will of the spouses, within the legal framework by taking fully collaboration in the adjustment of the consequences. This aspect conduct to the prenuptial agreement, the image of a legal remedy that comes to the benefit of children, too, according to the fact that the spouses in the contract conclusion, stipulate that they undertake to provide their children the same life even after marriage. In this contract the spouses may determine the obligation that they have in terms of creating and providing conditions for a peaceful family, of their children, independently of the spouses desire to be married or not. This forecast to contract marriage discharged the spouses from the responsibility for fictive and conditioned marriage, thereby giving more health to the family and the marriage, too, which in any given case, the life of children after divorce is not due to be a member of a fictive family. The commitment undertaken by the contract, in relation to obligation of alimony, for children of both spouses and the possibility of obtaining income therefrom by sending in their interest a part of spouses incomes, that will be evaluated by the court again, to evaluate all conditions that the law requires with respect to the contribution in the upbringing and education of children. In the contract may not be quantified the value of the contribute for the alimony, but is expressed the willingness that in case of the eventual marriage dissolution, the spouses in the quality of parents, determine which of the spouses shall make this payment and will be operated according the application parental responsibility .

The conditioning that finds this sanction is concerned with two aspects, the fact that the spouses can expresses themselves only in the fact that which spouse will hold the responsibility for the children growth, but in any moment can't abstain from this obligation and releases off the spouses from the consequences that can come from the dissolution of marriage. The most current problems are arranging children visits, a fact which is important for children to promote more the possibility of establishing a family life that parents has the obligation to create the possibility to meet the other parent that is not settle from the court. In these circumstances the forecast in the prenuptial agreement, is a double guarantee that at the time of the marriage bond, and the behavior of spouses at the time of the divorce and after it, is more understanding. Spouses are frequently in the total absence of information, up not knowing that the children after the divorce have the right to meet with both parents, that makes it possible for a family life and the spouses have the duty to implement the court's decision creating the best conditions for a family life. If the spouses can predict that in the prenuptial agreement, their will in relation to their obligation to the children and the commitment that takes each of them to fulfill the conditions for a family environment. Prenuptial agreement case, doesn't leave the husband surprised in relation of contract consequences, this sort of forecast is in the children interest, too, the children enjoyed the right to family life and parents to exercise parental responsibility unconditionally by divorce and social problems arising from the divorce.

\section{THE PRENUPTIAL AGREEMENT FINAL APPLICATION, FOR THE MARRIAGE DISSOLUTION CONSEQUENCES.}

The moment of entering into marriage, coupled with adjustment by prenuptial agreement, in relation to the property regime, reaches the highest level of validation and disposition of the free will of the spouses in respect of any consequence that

1 Gillow and Gillow v United Kingdom, date 24 November 1986, paragraph 46 
may come during and after the divorce.

Acquaintance these consequences reduces firstly the consequences for themselves, and secondly gives to the spouses the possibility to react in equanimity as it had anticipated at the time by their own will choosing the performance of conjugal and family life. Prenuptial agreement is limited to the inability to avoid the rights and obligations arising from the marriage, parental responsibility, rules of legal administration and custody, but the others they can regulate marriage contract without any difficulties encountered. Considering that our legislation, is crisscrossed by freedom contractor in connection with the subject of contracts within the type of regulation that made the prenuptial agreement, the spouses may choose, institutes of law in the contract, reinforcing them even more than the law, as guaranteed by their own free will. Specifically, the consequences of divorce are not provided that can be regulated by the prenuptial agreement, but are neither prohibited their sanctioning in the prenuptial agreement, would cause incorrect intervention in the selection of the right institutes. Not surprisingly, in this paper we addressed in an analogous agreement that fulfilled by spouses in case of divorce by mutual consent of the spouses, explaining that the effects of divorce can be left in the free will of the spouses, their prediction simply in the prenuptial agreement, shifts this deal in time considering that it is much more in spouse interest and children, if any, being prepared in the start that in the end. As the agreement presented to the court for dissolution of marriage by mutual consent of the spouses the prenuptial agreement, as well as its section for dissolution of marriage will be the subject of incidental interpretation where the spouses will be confronting the spouses free will with the law, and the concrete case with the prediction in prenuptial agreement. This is why it is deemed eligible that the prenuptial agreement should be evaluated from the court as a condition for the juridical power to protect the fundamental rights, that happens in the usage of the legal assets that court has. The existence of such a contract together with section regulating the consequences of divorce, only increased more aware of the obligations that derive from marriage and puts spouses on higher responsibility in protecting themselves and their children, if the court finds no derogation of liabilities, abuse and arbitrariness to the obligations and responsibilities of one spouse decides to approve it and its implementation of the free will of the parties. It is obvious that all the way that pursue this legal act that is done on behalf of the special protection for the family in front of the law to increase the security and the guarantee of the spouse and children rights. In conclusion this prediction, in the prenuptial agreement, only raise the possibility to prevent the hardest indication of the consequences of the marriage dissolution, transforming it in legal process and not in a social drama, as the most cases treat the divorce. 